\title{
Knowledge Of Benign Prostatic Hyperplasia And Ultrasound Screening Among Non-Academic Males Of A University Community In Enugu, South- East, Nigeria
}

\author{
O. Kalu, U. Abubakar, G. Luntsi, C. C. Ohagwu, V. K. Nwodo, C. Anyawu, M. O. Ezeobollo, \\ C. P. Ishiwu, and M. C. Ochie
}

\begin{abstract}
Benign Prostatic Hyperplasia (BPH) is a worldwide disorder among men. Studies have shown that high proportion of adult males have symptoms of benign prostatic hyperplasia in Nigeria. The aim of this work is to assess the knowledge of elderly men about prostatic hyperplasia and its implication which should prompt them to go for medical advice and also their knowledge of sonographic screening among males in the community. A prospective cross sectional study was conducted among non academics males of a University community in Enugu state south-East Nigeria, using a semi structured questionnaire. Informed consent was obtained from participants in the study, acceptance to participate was considered as consent. The questionnaire had two sections, A and $B$. Section $A$ assessed their demography including educational level and section $B$ assessed the objectives of the study which included knowledge of signs and symptoms as well as the risk factors of benign prostatic hyperplasia. The respondents with higher education had better knowledge of the disorder than those with lower education. A range of $75.4 \%$ to 96.7\% with a mean of $85.6 \%(\bar{x}=85 \%)$ did not know the signs and symptoms of benign prostatic hyperplasia. A range of $59.2 \%$ to $97.5 \%$ with a mean of $67.2 \%(x=67.2 \%)$ did not know the risk factors. $52.1 \%$ did not know that simple ultrasound screening could be carried out for benign prostatic hyperplasia. The knowledge of the signs and symptoms as well as the risk factors for BPH was higher among the more educated subjects. Generally, the knowledge was also poor among the educated. Therefore, apart from formal education, other forms of education are necessary to raise the knowledge in order to prompt the elderly men to seek medical advice. General education on benign prostatic hyperplasia to the public for both educated and lesser educated will enhance time of presentation for medical advise and hence better prognosis.
\end{abstract}

Index Terms - Protatic hyperplasia Knowledge, education, symptoms.

\section{INTRODUCTION}

The prostate gland is a walnut-shaped organ of the male reproductive system. It is not found in the female. It locates inferior to the urinary bladder between the bladder and the

Published on June 14, 2020.

O. Kalu, Evangel University Akaeze, Nigeria.

U. Abubakar, Usmanu Danfodiyo Universty, Nigeria.

(corresponding e-mail: umar.abubakar5@ udusok.edu.ng)

G. Luntsi, University of Maiduguri, Nigeria.

C. C. Ohagwu, Nnamdi Azikiwe University Awka, Nigeria.

V. K. Nwodo, Nnamdi Azikiwe University Awka, Nigeria.

C. Anyawu, Nnamdi Azikiwe University Awka, Nigeria.

M. O. Ezeobollo, University of Nigeria Nsukka, Nigeria.

C. P. Ishiwu, University of Nigeria Nsukka, Nigeria.

M. C. Ochie, University of Nigeria Nsukka, Nigeria. penis. The bladder and Urethra are parts of the lower urinary system. The urethra runs through the centre of the gland and when the gland is enlarged it disrupts urination. The prostate gland commonly becomes increasingly enlarge with age and the enlargement causes a common disorder among aging men.

Disease of the prostrate constitutes a significant portion of cases seen by urologist in males and is substantial source of morbidity and mortality among adult male population worldwide $^{1}$. Benign Prostatic hyperplasia (BPH) prevalence in Ghana is responsible for about $60 \%$ acute retention of urine and $28.6 \%$ haematuria [2]. Although prostate cancer, $\mathrm{BPH}$ and prostatis are known to affect prostate, $\mathrm{BPH}$ is the most common cause of prostatic enlargement and urologic disease suffered by elderly men ${ }^{[3]}$. Benign Prostatic hyperplasia is non cancerous but is a major cause of bladder outlet obstruction (BOO) and lower urinary tract symptoms (LUTS). The enlarged prostate gland makes urination difficult due to the pressure on the urethra when the organ becomes enlarged.

It was reported that one-in-four men older than 40 years have lower urinary tract symptoms suggestive of benign prostatic hyperplasia [4] in Nigeria but later in 2017 Ojewola and Ogundara [5] reported a prevalence of 57.4\% of LUTS on south west Nigeria [5]. This suggest that awareness needs be created among potential subjects who may have LUTS or symptoms of BPH to seek medical attention. $\mathrm{BPH}$ is the most common prostate problem affecting men above 50 years and an estimated $50 \%$ of men have histologic evidence of BPH by age 50 and $75 \%$ by age $80^{[5]}$. In the United states, BPH was one of the ten costliest disease in men older than 50 years of age [6]. The cooperation of men is important in the overall management of this condition to enhance early presentation for medical attention.

This study is to find out whether men know about BPH and the possible implication of the disorder.

The risk factors for BPH include age, family, history, obesity, heart disease, diabetes, lack of physical exercise and the symptoms include passing urine more often, weak stream of urine, difficulty in starting urine, dribbling at end of urine stream.

The study is also to know whether the men know ultrasound as tool for assessment of the prostate and some of the prostatic abnormalities [7]. Ultrasonography is cheap and available in developing nations. Better prognosis will be achieved if the subject with symptoms are aware of the importance of early intervention and treatment. This study 
assessed the elderly men in the study population of their knowledge about prostatic enlargement.

\section{Materials AND Methods}

This was a prospective cross-sectional survey among males of ages between 40-69 years of an academic community in an environment exposed to learning, public lectures and seminars. The total number of men was 658 . Using the Taro Formula [8], a sample size of 250 was obtained for the study. Two hundred and fifty structured questionnaires were prepared and distributed among the men selected by the inclusive criteria. The questionnaire had two sections, A and B. section A assessed the demographic data of the respondents. Section B assessed data on the objectives of the study which included knowledge of the risk factors, signs and symptoms of prostatic enlargement and also their knowledge of a possible diagnostic tool for screening for prostatic enlargement or benign prostatic hyperplasia. Medical terminologies were avoided as much as was possible in the questionnaire. Out of the 250 questionnaire distributed, 240 (96\%) were returned. The respondent who met the inclusion criteria were selected by convenience sampling method.

The data was analyzed using descriptive statistical method and presented in frequency tables, graphs and percentage.

\section{RESULTS}

Two hundred and fifty questionnaires were distributed and $240(96 \%)$ were returned.

\begin{tabular}{ccc}
\multicolumn{2}{c}{ TABLE I: AGE DISTRIBUTION OF THE RESPONDENTS } \\
\hline Age (Years) & Frequency & Percentage (\%) \\
\hline $\mathbf{4 0}-\mathbf{4 9}$ & 56 & 24 \\
$\mathbf{5 0}-\mathbf{5 9}$ & 98 & 41 \\
$\mathbf{6 0}-\mathbf{6 9}$ & 86 & 35 \\
Total & 240 & 100 \\
\hline
\end{tabular}

Table I above shows that age 50-59 years had the highest population of $98(41 \%)$ and age 40-49 years had a frequency of $56(24 \%)$ while age 60-69 had a frequency of $86(35 \%)$.

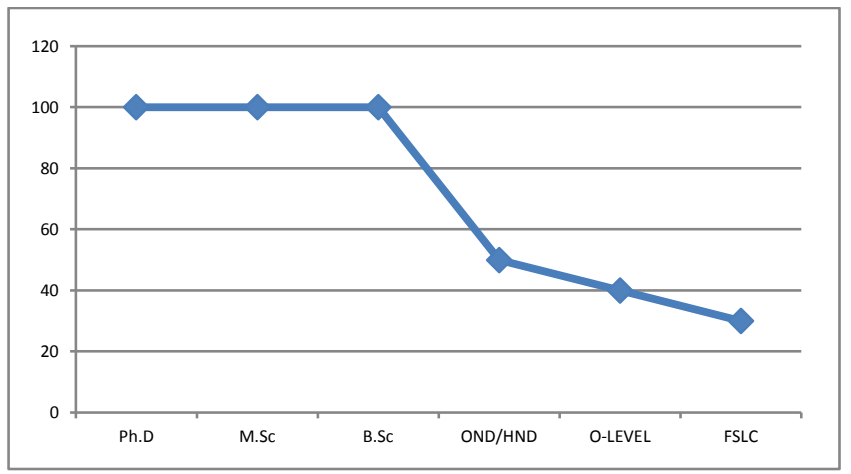

Fig. 1. Graph of Knowledge of Prostatic Enlargement Among Respondent of Various Educational Qualification in percentage.

In Fig. 1 the graph shows that the higher the educational qualification of the respondents, the higher their knowledge of prostatic enlargement as a health disorder among males.
TABLE II: KNOWLEDGE OF SIGNS AND SYMPTOMS OF BPH

\begin{tabular}{|c|c|c|c|}
\hline \multirow[t]{2}{*}{ Signs and symptoms } & \multirow[b]{2}{*}{ Frequency } & \multicolumn{2}{|c|}{ Percentage (\%) } \\
\hline & & Know & $\begin{array}{l}\text { Do not } \\
\text { know }\end{array}$ \\
\hline $\begin{array}{l}\text { Passing urine more } \\
\text { often }\end{array}$ & 51 & 21.3 & 78.7 \\
\hline Weak stream of urine & 54 & 22.5 & 77.5 \\
\hline $\begin{array}{l}\text { Difficulty starting } \\
\text { urine }\end{array}$ & 59 & 24.6 & 15.4 \\
\hline $\begin{array}{l}\text { Dribbling at end of } \\
\text { urine stream }\end{array}$ & 2 & 0.8 & 98.2 \\
\hline Failure to pass urine & 12 & 5.8 & 95 \\
\hline Do not know & 54 & 22.5 & 77.5 \\
\hline No response & 8 & 3.3 & 96.7 \\
\hline Total & 240 & 100.0 & $\bar{x} 85.6 \%$ \\
\hline
\end{tabular}

A range of $75.4 \%$ to $98.2 \%$ with a mean $(\bar{x})$ of $85.6 \%$ had poor knowledge of the signs and symptoms of BPH.

TABLE III: KNOWLEDGE OF RISK FACTORS AMONG RESPONDENTS

\begin{tabular}{lccc}
\hline Risk factor & Frequency & Know \% & $\begin{array}{c}\text { Do not Know } \\
\text { \% }\end{array}$ \\
\hline Old Age & 98 & 40.8 & 59.2 \\
Family History & 40 & 16.6 & 83.4 \\
Obesity & 6 & 2.5 & 97.5 \\
Lack of exercise & 6 & 2.5 & 97.5 \\
No Idea & 83 & 34.6 & 65.6 \\
No response & 7 & 3.0 & 97.0 \\
Total & 240 & 100.0 & $\bar{x}=67.2$ \\
\hline
\end{tabular}

A range of $59.2 \%$ to $97 \%$ did not know the risk factors of BPH $(\bar{x}=67.2)$.

TABLE IV: KNOWLEDGE OF SONOGRAPHY FOR ASSESSMENT OF BPH

\begin{tabular}{lcc}
\hline & Frequency & Percentage \\
\hline Yes & 95 & 39.6 \\
No & 125 & 52.1 \\
No response & 20 & 8.3 \\
Total & 240 & 100 \\
\hline
\end{tabular}

$52.1 \%$ of the respondent did not know about Sonography as an assessment tool for BPH and $8.3 \%$ had no idea.

Knowledge about prostatic enlargement by elderly is important factor in the management of the disorder and will improve condition if the subjects know and promptly reported, this will avoid further complication which make treatment difficult [9].

\section{DISCUSSION}

Prostatic enlargement is a worldwide male disorder, although often may present late for medical attention. This is a study to assess elderly men's knowledge of prostatic enlargement. This study was carried out on men from 40 to 69 years. The age distribution of the respondents showed that the age of 50-59 years had the highest frequency of 98 $(41 \%)$ while the age of 60-69 years had a frequency of 86 (35\%). The age of 40-49 years had $56(24 \%)$ respondents. All the respondent who have $\mathrm{PhD}, \mathrm{MSc}$ and $\mathrm{BSc}$ knew about prostatic enlargement (Benign Prostatic hyperplasia). The first school leaving certificate (FSLC) holders had poor knowledge of prostatic enlargement as a disorder among men. The work of Robert and Benedict support the opinion that education is a fundamental social determinant of health [10]. The lower the educational qualification the lower the knowledge of prostatic enlargement (Fig. 1), from Robert and Benedict work, the poorly educated will have poor 
knowledge of the morbidity of prostatic enlargement as a health disorder among men. The respondents had poor knowledge of the signs and symptoms of BPH. A range of $75.4 \%$ to $96.7 \%$ of the respondents, that is a mean population of $85.6 \%(\bar{x}=85.6 \%)$ did not know the signs and symptoms of BPH. Lack of knowledge of a disease is a factor to makes them neglect to come late for medical advice. The delay to present to hospital and the complication arising from prostatic enlargement play a role in the occurrence of death [11]. The patient factors in getting health care were related to awareness, and the subjects perceived severity of the condition in a study by Geoffrey et al., in Uganda [12]. Patient try to cope with diseases if there is no immediate sense of severity and would not seek quick medical advice especially in developing nations. There is strong evidence that lower education and lesser income status contribute to patient delay for medical advice[13]. In developing nations, patients present late with very large prostate and sometimes comorbid medical conditions and complications. Most urologist will prefer removing glands in the range of 50-75 $\mathrm{g}$ instead of larger ones that are more difficult to handle [14]. In spite of the presenting signs and symptoms, blacks, say men delay seeking medical advice until their symptoms becomes severe. The poor knowledge of the implication of the symptoms is a hindrance to quick effort to seek medical advice until there is severe pain. There was also poor knowledge of risk factors. A mean percentage of $\bar{x}=67.2 \%$ did not know the risk factors of prostatic enlargement. The score of those who did not know the risk factors ranged from $59.2 \%$ to $97 \%$. Low knowledge of risk factors would set a trend in late presentation in the developing nations especially hence creating complication in treatment [9]. Various language and forms of education should be used to disseminate information about prostatic enlargement disorder among men. Information about the signs, symptoms, risk factors should be disseminated. Only $39.6 \%$ knew that a simple ultrasound screening can be carried out via ultrasound screen to assess the course of the symptoms in the management of prostatic enlargement. Ultrasound should be available in the communities to help the health care givers or the clinician assess patients for prostatic enlargement.

\section{CONCLUSION}

Knowledge and education are a factor in patient with symptoms of benign prostatic hyperplasia, the poorly educated men did not have good knowledge of the signs, symptoms and risk factors for prostatic enlargement while educated men had a better knowledge of it. Poor knowledge of BPH will cause late presentation for medical advice. The late presentation is stated as a factor in complication of $\mathrm{BPH}$ as well as the late treatment. If the men have better knowledge of BPH, the subject will present earlier for better prognosis. Therefore, there should be education to increase awareness about the disease like is done for many other diseases. Education about BPH should be carried to the communities in the developing countries to teach the essence of reporting early for medical advice. Education will enhance knowledge of the males about prostatic enlargement and treatment and help to prevent life.

\section{ACKNOWLEDGMENT}

The authors would like to acknowledge the research assistants, the mobilisers, the study participants, and the management of University of Nigeria, Enugu Campus. This study has received funding from the management of Evangel University Akaeze, Nigeria.

\section{REFERENCES}

[1] C. C. Nwafor, O. S. Keshinro and E. K. Abudu, "A histopathological study of prostate lessons in Lagos Nigeria: A private practice Experience," Nigerian Medical Journal, vol. 56(5), pp. $338-343$, 2015.

[2] E. D. Yeboah, "Prevalence of Prostatic Hyperplasia and Prostate Cancer in Africa and Africans in Diaspora," Journal of West African College of Surgeons. vol 6(4), pp. 1-30, 2016.

[3] E. Cecc, and L. V. Ezeanyika, "Metabolic syndrome in subsahara Africa. Smaller twin of a region; Prostatic Disease," Int. Urology, Nephrology. vol. 40: pp. 909-920, 2008.

[4] L. V. Ezeanyika, E. Cecc, O. Obidoa, and S. O. Elom, "Prostate Disorders in an apparently normal Nigerian Population," Prevalence Biokemistri, vol. 18: pp 127-132, 2006.

[5] R. W. Ojewola, and E. O. Ogandara, "Prevalence of Clinical Benign Prostatic Hyperplasia amongst Community men in South-west Nigeria/Rural setting. A cross sectional study," African Journal of Urology, vol. 23(2), pp. 109 - 115, 2017.

[6] Enlarged prostate Medline Plus, www.nlminih.gov [accessed $6^{\text {th }}$ June 2020].

[7] E. H. Kim, J. A. Larson, and G. L. Andriole, "Management of Benign Prostatic Hyperplasia," Annual Review of Medicine, 2016: vol. 67, pp $137-151,2016$.

[8] T. Yamane (1967) Statistics: An introductory Analysis, $2^{\text {nd }}$ ed. New York, U.S.A: Harbour and Row, pp 4, 1967.

[9] I. A. Gadam, A. Nuhu, and S. Nuhu, "Ten Year Experience with open prostatectomy in Maiduguri. ISRN Urology, vol. 2, pp 1-4, 2012.

[10] S. Affutato, M. Scarpa, S. Lecca, S. Issognic, and G. G. Cancarini. Difficult and delayed Diagnosis of Prostatic Involvement in Granulomatosis with polyangiitis, Rheumatology, vol. 58 (2), pp 9 , 2019.

[11] R. A. Hahn, B. and Truman, "Education improves Public Health and promotes Health Equity," Int. Journal of Health Service, vol. 45(4), pp 657-678, 2005.

[12] L. A. Chavane1, P. Bailey, O. Loquiha, M. Dgedge, M. Aerts and M Temmerman, "Maternal death and delays in accessing Emergency Obstetrics care in Mozambique," BMC Pregnancy Child Birth, vol. 18, pp 71, 2018.

[13] G. Musinguzi, S. Anthierens, F. Nuwaha, J. V. Geertruyden, R. K. Wanyenze, and H. Bastiaens, "Factors influencing compliance and Health seeking Behaviour for hypertension in Mukono and Buikwe in Uganda: a qualitative study," International Journal of Hypertension," vol. 59, pp 1-13, 2018.

[14] K. Sharma, A. Costas, L. N. Shulman, and J. G. Meara, "A systematic Review of Barrier to Breast Cancer care in Developing Countries Resulting in Delayed Presentation," Journal of Oncology, vol. 27, pp $5-8,2012$.

[15] I. Blanks, "Real Risk of losing older men in the workplace due to incontinence" Global forum in incontinence, June 2012. 